Marquette University

e-Publications@Marquette

College of Education Faculty Research and

Publications

Education, College of

$1-1-2011$

\title{
What's the Point?: An Exploration of Students' Motivation to Learn in a First-Year Seminar
}

Jody E. Jessup-Anger

Marquette University, jody.jessup-anger@marquette.edu

Accepted version. The Journal of General Education, Vol. 60, No. 2 (2011): 101-116. DOI. (C) 2011

The Pennsylvania State University. Used with permission. 
Marquette University

\section{e-Publications@Marquette}

\section{Education Faculty Research and Publications/College of Education}

This paper is NOT THE PUBLISHED VERSION; but the author's final, peer-reviewed manuscript. The published version may be accessed by following the link in the citation below.

Journal of General Education, Vol. 50, No. 2 (2011): 101-116. DOI. This article is C Penn State University Press and permission has been granted for this version to appear in $\underline{\mathrm{e}}$ Publications@Marquette. Penn State University Press does not grant permission for this article to be further copied/distributed or hosted elsewhere without the express permission from Penn State University Press.

\section{Contents}

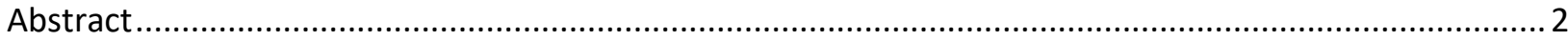

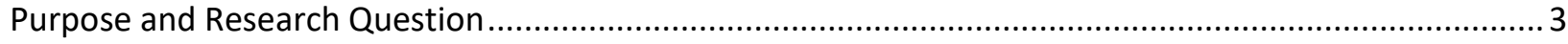

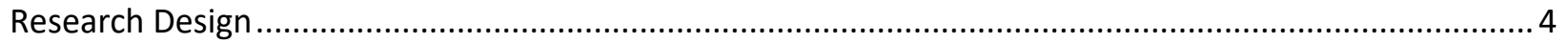

Procedure

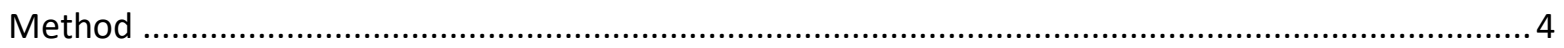

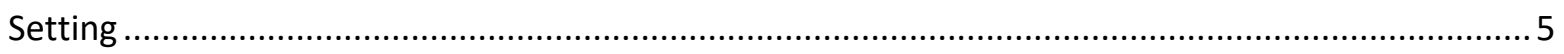

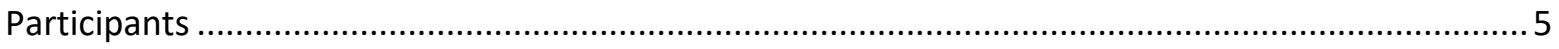

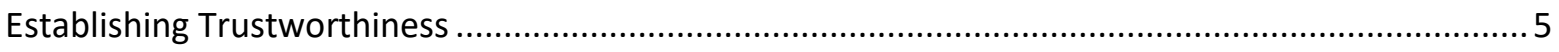

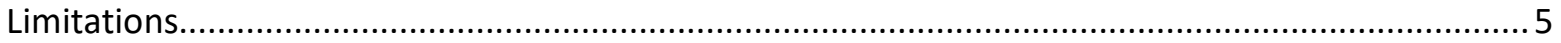

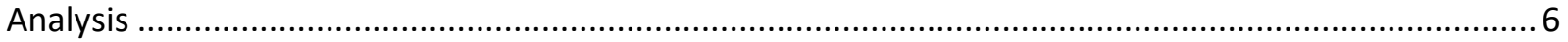

Findings

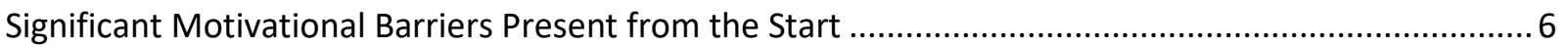

Students' Personal Connection to the Subject Matter Enhanced Their Motivation to Learn ................. 8

Pedagogical Strategies Served to Deepen Students' Motivation ...................................................... 9

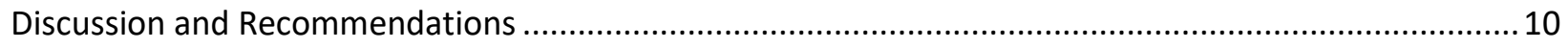

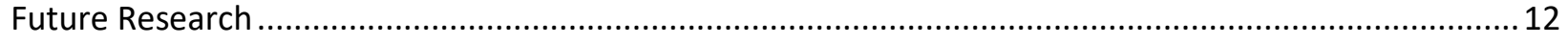

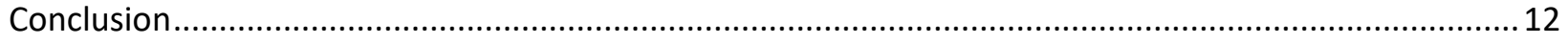

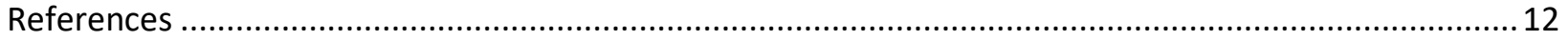




\title{
What's the Point?: An Exploration of Students' Motivation to Learn in a First- Year Seminar
}

\author{
Jody E. Jessup-Anger
}

Department of Educational Policy and Leadership Studies, Marquette University, Milwaukee, WI

\section{Abstract}

This qualitative case study explores how undergraduate students and their instructor made meaning of students' motivation to learn in a one-credit, pass/fail first-year seminar. The findings point to the importance of addressing structural motivational barriers and ensuring that instructors possess the instructional, motivational, and developmental strategies necessary to foster motivation.

Since the mid-1980s, first-year seminars (also called freshman seminars) have become a staple at many postsecondary institutions. A 2002 survey conducted by the National Resource Center for the First-Year Experience and Students in Transition revealed that over 70 percent of institutions offer first-year seminars, "making them the most common and pervasive first-year intervention tool on the part of colleges and universities across the country" (Keup \& Barefoot, 2005, p. 12). Administrators and policy makers hoped that these seminars, initiated amid concerns about undergraduate retention and perceived fragmentation of the undergraduate curriculum (Barr \& Tagg, 1995; Duderstadt, 2000), would provide a foundation for the undergraduate student experience, serving primarily to assist students in making the transition from high school to college and to motivate them to take advantage of everything a university has to offer (Boyer Commission on Educating Undergraduates in the Research University, 1998). Although there is some variation across campuses in the way first-year seminars are organized (numbers of credits, length of course, topic), they are generally configured as small (under twenty students), credit-bearing courses that are taught by faculty and staff (Barefoot, 1992). Typically, the aim of a first-year seminar is "to enhance the academic and/or social integration of first-year students by introducing them to (a) a variety of specific topics which vary by seminar type, (b) essential skills for college success, and (c) selected processes the most common of which is the creation of a peer support group" (Barefoot, 1992, p. 49).

Existing research has illustrated many positive outcomes associated with first-year seminars, especially related to improvement in retention from first to second year and subsequent graduation rates (Barefoot, Warnock, Dickinson, Richardson, \& Roberts, 1998; Fidler \& Godwin, 1994; Fidler \& Moore, 1996; Simmons, 1995). Other studies have connected first-year seminar participation to academic performance and student engagement (Fidler \& Hunter, 1989; Keup \& Barefoot, 2005; Koch, 
2001). In their longitudinal national study of first-year seminar outcomes, Keup and Barefoot (2005) have found that first-year seminar participation was related to numerous positive academic experiences for students, including interacting informally with faculty, participating in class discussion, collaborating academically with other students, and course attendance. Furthermore, students who took first-year seminars were more likely to develop a network of friends on campus (Keup \& Barefoot, 2005). These findings illustrate that first-year seminars are meeting many of their intended outcomes.

Less empirical attention has been paid to understanding the process aspect of first-year seminar participation. Enduring questions remain about how students' experiences in a first-year seminar affect the way they make meaning of their educational endeavors.

\section{Purpose and Research Question}

In the current study, I sought to explore how students in a pass/fail, one-credit, first-year seminar made meaning of their experience, particularly in relation to their motivation to learn. Proponents of first-year seminars envision that these courses, in addition to facilitating their transition experience, will motivate students by introducing them to the "wealth, diversity, scale, and scope of what lies ahead [for them at the university]" (Boyer Commission on Educating Undergraduates in the Research University, 1998, p. 19).

Motivation is a "theoretical construct used to explain the initiation, direction, intensity, persistence, and quality of behavior, especially goal-directed behavior" (Brophy, 2004, p. 3). In a classroom setting, motivation to learn explains students' investment and interest in varying pursuits (Brophy, 2004). The role of a first-year seminar in setting a foundation for motivation is critical, as it may determine students' willingness to commit to engaging in their academic work (Boyer Commission on Educating Undergraduates in the Research University, 1998) and ultimately may be the difference between students redoubling their efforts in the face of adversity or leaving school.

Many motivational theorists conceptualize motivation as a product of expectancy and value reasoning within the broader social milieu (Brophy, 2004; Svinicki, 2004; Wigfield \& Eccles, 2000). The expectancy component of the motivation equation explores students' beliefs about their ability in relation to a task or outcome, whereas the value reasoning component of the equation explores students' beliefs regarding the overall worth of the process and the reward (Brophy, 2004). The social milieu is the context in which the motivation occurs, which might be in a classroom, on a ball field, or in a work setting.

The current study drew primarily from goal theory, an expectancy theory positing that students' differing goals in an achievement situation (such as a class) contribute to different outcomes (Brophy, 2004). Dweck and Leggett (1988) have developed a model illustrating how underlying psychological processes lead students to choose different goals in achievement situations. The model suggests that some students in a classroom setting believe that intelligence is fixed (that it is either adequate or inadequate for the task at hand), whereas others believe intelligence to be incremental (that improvement can happen over time with practice and hard work). Ultimately these underlying beliefs affect behavior. Students with a fixed belief about intelligence orient their goals toward performance, focusing on either gaining positive judgment about their intelligence from the instructor or their peers or avoiding negative judgment. Students with an incremental belief about intelligence orient their goals toward learning or mastery, focusing on increasing their competence. When students encounter a 
difficult task, performance-oriented students would respond in a helpless manner by trying to avoid challenge or save face. Learning- or mastery-oriented students would respond to a difficult task by redoubling their efforts, continuing to persist in spite of the difficulty. Although there has been some debate about the value of some performance-oriented goals as motivating when a student is a high achiever (Harackiewicz, Barron, Pintrich, Elliot, \& Thrash, 2002; McGregor \& Elliot, 2002), generally evidence supports researchers' recommendations that instructors avoid encouraging students to adopt performance goals in lieu of mastery or learning goals (Brophy, 2004; Middleton, Kaplan, \& Midgley, 2004). Goal theory is relevant to the current study because it provides a framework for understanding how students' behavior in the first-year seminar may relate to their motivation.

Also relevant to the current study because of its focus on the role of grades and motivation is a value reasoning study conducted by Sarafino and DiMattia (1978), who proposed a hypothetical course and asked students to choose whether they would take the course for a letter grade or a pass/fail demarcation. They examined how students' believed their grade type selection would affect their intrinsic interest and effort in the course. The researchers found that when students expressed high interest in taking a course, those who were in the pass/fail group predicted that they would study more than the students in the A-F group. Hence, the researchers (1978) conclude that for the students who were both highly interested in taking the class and in the A-F group ( $16 \%$ of the students), motivation would be undermined because of the A-F grade demarcation, and when interest was moderately high, the effect was reversed, with students in the A-F group predicting that they would study more than the students in the pass/fail group. There was no effect of either group on creativity of assignments or personal satisfaction. Students' predicted attendance declined as their interest in the class declined, with no changes between the pass/fail and traditional A-F grading groups. The researchers conclude that a majority of students would benefit from grades, as the interest had to be very high in the course in order for grades to undermine motivation. When taken together, goal theory (Dweck \& Leggett, 1988; Grant \& Dweck, 2003) and the Sarafino and DiMattia (1978) study raise questions about the appropriateness of a pass/fail first-year seminar as a means for enhancing students' motivation to learn.

\section{Research Design}

The purpose of the study was to explore how students enrolled in a one-credit, pass/fail first-year seminar made meaning of their motivation to learn throughout the course. A constructivist epistemology guided the research study. A single-case-study, qualitative approach focused the data collection and analysis procedures (Yin, 1984). This approach was appropriate given my desire to gain understanding of the classroom setting and my awareness that the environment might influence the way that students described their experiences, thus making it beneficial to elicit students' voices in their natural setting (Creswell, 2007).

\section{Procedure}

Method

Consistent with case study research, in which multiple angles are taken to examine a bounded context (Creswell, 2007), several methods were employed to investigate the research question. First, I observed the classroom setting on three separate occasions throughout the ten-week class: during the second week, sixth week, and final week. I chose to attend class sessions where I believed discussion and student/instructor interaction would be greatest, as opposed to sessions when the class would spend 
most of their time watching a movie. During my classroom observations, I took notes of the pedagogy employed by the instructor, the students' engagement with the material, and the interactions among the students and with the instructor. Second, I conducted one-on-one, semistructured interviews with four of the nine students in the class, exploring their reasons for taking the class, their experiences with the class, and their beliefs about the class in relation to other classes and to their overall collegiate experience. Third, I conducted a semistructured interview with the class instructor, exploring her beliefs about the students' motivation and her role in fostering their motivation. Finally, I obtained copies of students' final written course evaluations in order to understand more about the context and what they believed were the important aspects of the course and how these aspects might relate to motivation. In addition, I collected documents including the course syllabus, assignments for the reflection papers, and several of the readings in order to obtain more information about the organization of the class, activities, and processes (Patton, 1990).

Setting

The study was set in a one-credit, pass/fail, first-year seminar at a large, research-extensive university in the Midwest. The seminar focused on fictional narratives related to transition. I chose to examine the particular section because its focus might appeal to students for motivational reasons such as their interest in transition and coming-of-age stories, desire to improve competence in the transition process, and desire to build relationships with other students.

The course met once each week during the first ten weeks of the spring 2007 semester. There were nine students in the class, six women and three men. Assignments included weekly readings of short stories, weekly reflection papers, and a final project. The structure of the class was discussion based. The instructor held a doctorate in English and was an administrator working in the area of faculty development at the university.

\section{Participants}

Purposive and convenience sampling strategies were used to select participants for the interview portion of the study (Patton, 1990). All participants in the transition-related section of the first-year seminar were identified for possible inclusion in the study. After I explained the purpose of the study to the students in the class, four of the nine students agreed to be interviewed, as did the instructor. All of the students interviewed were first-year students, lived on campus, and were either eighteen or nineteen years old. Three were female. Three identified as white, and one identified as multiracial. The participants chose or were assigned the following pseudonyms to protect their confidentiality: Prue, Addison, Maria, and Scott.

\section{Establishing Trustworthiness}

Several steps were taken to ensure the trustworthiness of the research process (Creswell, 2007), including transcribing all interview data verbatim, sending synopses of the interview back to participants to ensure accurate representation, corroborating participants' responses with interview and observation notes, gathering data at different points in time and through different means, and discussing results of the data with several colleagues.

\section{Limitations}

Although steps were taking to ensure that the data collected reflected the students' views and experiences, several limitations are important to note. First, because a single-case-study approach was 
used, comparisons across seminars were impossible to make. Second, despite my desire to interview all the students enrolled in the class, several stated that they were too busy with other commitments to participate in the interview portion of the study. As a result, although their behavior in class was observed, their meaning making regarding their motivation remains unknown.

Analysis

Data analysis was initiated by reading all transcripts, observation notes, and course documents to provide a broad overview of the context of the course. Then, using Creswell's (2007) data analysis spiral, in which "the researcher engages in the process of moving in analytic circles rather than using a fixed linear approach," I analyzed the data in a constant comparative manner (p. 150). I coded the transcripts, observation notes, and documents and then looked for emergent patterns in the codes. I went back to the data with the emergent codes in mind. Consistent with a case study approach (reswell, 2007), as patterns emerged from the varying sources, I connected them into descriptive themes, which are presented below.

\section{Findings}

Three noteworthy themes emerged from the observations, transcriptions, and course documents regarding students' meaning making about their motivation to learn in the context of a pass/fail, onecredit, transition-focused first-year seminar. These themes were as follows: significant motivational barriers were present at the beginning of the class; students' personal connection to the subject matter enhanced their motivation to learn; and pedagogical strategies served to deepen students' motivation to learn.

\section{Significant Motivational Barriers Present from the Start}

Interviews with students and the instructor revealed motivational barriers embedded in the structure of the class as well as in students' reasons for taking it. Structural barriers to motivation included limitations perceived by both the students and the instructor because the class was worth one credit, was pass/fail, and was not a formal focus of the instructor's job responsibilities.

The instructor and several students explained that the fact that the class was one credit diminished their expectations for work in the course. The instructor believed that she could not be as demanding in assignments or readings as she might have been in a three-credit class, nor could she expect as much from the students. She explained, "I felt that for a one-credit course on this topic, they do the work and they're here, that's more than half the battle, you know what I mean. . . I couldn't provide the same kind of structure, or analysis, or expect the same kind of preparation that I would in a three-credit, sixteen-week class. I just had to relax a little bit more in the kind of expectations I had." The instructor shared that she attributed students' poor writing during the first few weeks of class to the fact that the class was pass/fail. She believed that students needed to prioritize their time and that, because of the pass/fail demarcation, her class was not high on their list of priorities.

Several students echoed the instructor's perception, explaining that they signed up for the class because it was only one credit and they needed a credit. Coming into the class, the students did not expect to work hard. Maria expressed her surprise at the work load in the class. She explained, "I didn't expect to have a paper a week, and, you know, read like two stories, which isn't that bad, unless you 
leave it to the last minute like I do sometimes. I don't have to do that [much work] for most of my classes that are like, four credits, and this is just one credit."

In addition to the class being one credit, the pass/fail demarcation served as a perceived and real barrier to motivation. The instructor described how she believed that students approached a pass/fail class differently than a traditional A-F class. She explained,

The most challenging aspect was maximizing their learning, their learning opportunities, with such a short amount of time and a pass/fail [demarcation]. Because, I feel like with the pass/fail, a lot of them took that as, "Oh well, I don't have to try so hard because it's a pass/fail." So, I felt like getting them to work hard and try in a pass/fail setting, in a one-credit, in ten weeks, is hard. I felt the challenge was to make it meaningful . . . given the students, the carrot at the end of the stick for a lot of them is a grade. . . If that's their main motivation, I can't use that here.

Surprisingly, when I interviewed the students, three of the four admitted that they did not realize the class was pass/fail until I came into their class to recruit students for the study, despite the fact that it was clearly outlined in their syllabus. Scott, the only student interviewed who knew from the start that the class was pass/fail, described what he initially expected the class to be like. He explained, "My roommate had [a pass/fail class] last semester ... and he would bust out his paper on a Sunday night if his class was on Monday. So what I thought about [the class] was just like, 'Oh, this will be nothing, it will be the sort of class I can just push aside... . What I thought about it was almost, probably what most people think about a pass/fail class, which is, 'I am going to do just enough to pass and forget about it, not make it a major priority."'

Prue expressed surprise at learning that the class was pass/fail but even more surprise that the other students were showing up to class every week and discussing the material. She admitted that she would probably have approached the class differently had she known from the start that it was pass/fail, and she was grateful that she had not known because she doubted that she would have put forth the effort to engage in the class. Addison was also surprised by the news that the class was pass/fail. She explained that she did not "have a problem" with the pass/fail demarcation because "if you fail it, you obviously aren't doing what is required, which is just writing a paper for each week ... it's nothing, just write it."

In addition to the class structure impeding motivation, the instructor explained that the time and effort she put into course preparation were limited as a result of the class not being part of her formal job responsibilities and because she was not paid to teach it. She explained, "Because it's not my job and I am not getting paid, it is something that I, I take it seriously, but I don't . . put nearly as much thought [and] hours of time into it than I would if I were (a) getting paid or (b) it was a three-credit class. That's not to say that I don't . . care about it, it's just that l've made it fun in part for a reason, because if it's not fun for me, I'm not going to do it."

When asked how getting paid might influence her preparation, the instructor explained that she would feel more of a sense of responsibility for the class and would prioritize it. Interestingly, the instructor's self-described limited preparation for the course was not evident to me when I observed the class. During each of the three classes I observed, the instructor brought in an outline for the class session, recounted information from the readings, and in two of the three classes, handed back papers. 
Furthermore, in my interviews with students, there was no mention that they found the instructor to be poorly prepared or unmotivated to teach the class.

In addition to structural impediments to motivation, students' attitudes served as barriers to the class initially. Scott, who described taking the class because of intrinsic interest, explained his attitude upon entering the class, "The first two weeks into it I was like, 'Okay, boring, let's get through this, the caf $[$ sic] is going to close soon." Prue felt similarly, as she was signed up for a first-year seminar focused on comic books initially but was reassigned into the transition-focused class. She explained, "At first I wasn't happy about it because I was like, 'Oh, coming of age, I don't know. That doesn't really sound like something I would pick.' . . . I thought it was going to be . . . all generic kinds of stories and really trite stuff." The other students described signing up for the course because it seemed easy, they wanted to watch movies, or they needed one more credit.

The instructor explained that the students' initial lack of motivation was a departure from the last time she taught the course, during which students expressed much greater interest in the class from the beginning. As a result of their limited intrinsic motivation, she took it upon herself to spend more time engaging them in conversation and finding creative ways to connect them with the material than she had previously. Based upon my observations in class and interviews with the students, the instructor's efforts to motivate the students paid off, as most of them expressed or demonstrated interest in and excitement about the material toward the end of the course, despite their initial apathetic attitudes.

\section{Students' Personal Connection to the Subject Matter Enhanced Their Motivation to} Learn

Several students described how their personal connection to the subject matter served as a tool for motivation. Scott, in discussing how he shifted from the mind-set of tolerating the class to prioritizing it, explained, "About the second week, we started doing more readings... . We would get questions [where] we had to reflect on our own lives. And reflection on our own lives would really make you think about what you've gone through in the last year and a half, so that ... probably just motivated me to think, 'Wow, I should really try at this.'"

Scott went on to describe how the class had a profound influence on him because he had never analyzed himself before. He explained that as a result of the relationship between his personal experiences and the class material he was becoming more academically focused and was putting the final touches on an application to transfer to a film school in New York. Although he struggled with his writing, he shared that the writing assignments and discussion in class had helped him to reflect his transition experience in a way that he might not have otherwise, thus serving as a tool for motivation.

For Addison, her personal connection to the subject matter was not as transformative or as easy as it was for Scott. Addison explained that she enjoyed writing papers where she was encouraged to reflect on her own experiences but sometimes had difficulty "going deeper" because she felt like she was still growing up and was not ready to analyze her feelings about transition. She also explained that the small class size sometimes caused her to hold back in class discussions because she feared judgment from her peers and the instructor. That said, she reported that the most beneficial aspect of the class was the connection between the subject matter and her personal life, because "it really makes you think 
about who you are and actually analyze what you go through instead of going through your life, like, floating through it."

All of the students interviewed shared that connecting the subject matter to their personal lives made the class more interesting because it gave them insight into what their peers were going through in addition to increasing their own self-awareness. The extent to which the connection between self and subject matter served to motivate the students varied, as some students, like Maria, already had experiences connecting their own experiences with their academic pursuits and found the technique less novel, whereas others, like Scott, were being exposed to a completely new framework.

The connection between students' personal experiences and the subject matter was intentional. In fact, the course objectives reflected the instructor's desire to blur the lines between students' analysis of the academic content and their personal experiences in order to enhance their learning. The instructor explained that connecting curricular content to students' personal lives is a principle of teaching and learning, and she described how she went about integrating the two, stating: "I felt as the class went on, I would help them look at the complexities of the stories, which I hoped would also help them to see their lives in a more complex way and less like, 'Oh, my parents are evil,' or you know, friendship is a complicated organism, it's not, 'This is my best friend forever.' . . I wanted them to, as they engaged in the complexities of the texts, transfer that to their own understanding of their lives."

I saw evidence of the integration of academic content and personal reflections in the class discussions, reflection papers, and final project. The following is an example of a class assignment that integrated academic and personal material: The assignment reads, "Explain in your own words what Annie Dillard is saying about her own childhood in this essay *and* what she is trying to tell the reader about the process of growing up. Do you identify with her descriptions of 'waking up' and becoming aware of presence and loss simultaneously? Provide an example/experience from your own life to either support or refute her observations."

\section{Pedagogical Strategies Served to Deepen Students' Motivation}

In addition to enhancing motivation through the integration of academic content and personal experiences, the students described the course, and the instructor in particular, as coaching them on how to improve their writing and analytic skills and also fostering the importance of improving these skills. Brophy (2004) explains that it is important for instructors to aim their instructional strategies and content toward connection with students' cognitive zone of proximal development (Vygotsky, 1978), recognizing the students' current skill level and aiming to provide tools and support to increase their cognitive complexity. He also encourages instructors to focus on students' motivational zone of proximal development, recognizing students' current level of appreciation for a task and helping them learn to appreciate the value of the task more or to value a task that they have not yet come to appreciate. Aiming instructional strategies at students' motivational zone of proximal development in addition to aiming them at students' cognitive zone of proximal development will ensure that students learn the material but also will encourage students to take a more vested interest in learning more material, thus increasing their motivation to learn.

The instructor's questioning strategies made it clear that she was working in her students' cognitive zones of proximal development. During every class session I observed, the instructor listened to students' responses and then challenged them to go deeper. "Good, now what's under that 
presenting symptom?" she asked, or, "I hear what you are saying, you could say that the life lesson here is what?" In her interview, the instructor discussed how she hoped to move the students to think more analytically. She explained, "I am hoping they move from a passive observer of a film or a consumer of a short story to see that there is meaning to be gleaned."

The instructor also appealed to students' motivational zone of proximal development, although she did not address her desire to do so in our interview. Several students described their learning in a way that led me to believe that they had developed not only cognitive skills while in the class but also an appreciation for why the skills are important beyond the class and thus motivation to continue improving. Scott discussed how his writing skills as well as his approach to writing improved throughout the class because of the feedback given to him by the instructor. He explained, "You get the paper back, and you flip through it. There would be markings, like there would be a section she [the instructor] would mark off and say, 'Go more in depth here.' If you go more in depth, you can actually expand on that to another page.... We can almost take that topic and make it a whole paper.... So feedback helped the future weeks [because] you would start writing your paper the next week, and you think, 'Well, why am I talking about this? . . that's something everybody knows.'”

Scott went on to say that the feedback was helping him in other classes, especially other writing classes, in which he felt like he needed a lot of help. The feedback was also helping him to garner an appreciation for good writing, which he believed he needed in order to realize his dream of working in film. He gained an appreciation for the importance of writing not only for school but also for life in the same way that he gained an appreciation for personal reflection, as mentioned earlier.

Prue and, to a lesser extent, Maria both echoed Scott's views that they gained an appreciation for the importance of the role of feedback in improving their writing, not only for the purpose of passing the class but also for building their writing skills for life. Not only were students' cognitive zones of proximal development engaged, their motivational zones were engaged as well.

\section{Discussion and Recommendations}

The findings of the current study illustrate the complexity of how students made meaning of their motivation to learn in a one-credit, pass/fail first-year seminar. Despite the fact that most students were unaware of the pass/fail grade demarcation at the beginning of the semester, they described A-F grading as a form of extrinsic motivation and explained that initially they would not have taken or did not take the class as seriously because it was a pass/fail class. These findings are consistent with Sarafino and DiMattia's (1978) findings, which illustrate that grades detract from motivation for only the most motivated students and otherwise they serve as a form of extrinsic motivation. Furthermore, the instructor perceived the absence of A-F grading as a barrier, in spite of the fact that three of the four students I interviewed were unaware that the class was pass/fail. The instructor's faulty perception initially caused her to attribute the students' poor writing to a lack of effort as opposed to a lack of ability or clarity regarding expectations, which could have had detrimental effects on the way she approached the students and also on her own motivation for teaching the class.

The findings did not apply cleanly to Dweck and Leggett's (1988) distinction between masteryand performance-oriented goals. None of the students interviewed expressed the desire to outperform peers, and when they made normative comparisons, it was typically to illustrate admiration that their peers were working hard in spite of the class being pass/fail. Brophy (2004) has raised concerns with 
Dweck and Leggett's categorization of "performance goals" because when left to describe their goal orientations outside of a forced-choice survey, few students in empirical studies Brophy conducted or examined described goals in which they made comparisons between themselves and their peers. The findings of the current study support his concerns. Brophy suggests that researchers phase out the use of the term performance goal and begin to differentiate between learning-mastery goals and validation goals, which relate to students' desire to confirm their ability in an achievement situation. He also proposes adding a third type of goal orientation, which he labels "outcome" goals. These goals are more focused on task completion for the sake of reaping potential rewards, like parent approval, graduation, getting a job, or the attainment of additional opportunities.

Perhaps the most important finding of the current study is the change in students' motivation in response to the instructional strategies employed by the instructor. Despite the students' initial lack of motivation, to varying degrees their motivation increased throughout the course. They specifically discussed the importance of the feedback they received on papers. The constructive feedback coupled with the modeling of analytic reasoning employed by the instructor in the classroom not only helped the students strengthen their writing and analysis abilities but also fostered an appreciation for such skills that students would take with them beyond the confines of the classroom into their other classes and their day-to-day lives. This finding supports Brophy's (2004) call for instructors to provide scaffolding for students to deepen their appreciation for learning in addition to challenging them to expand their ability to learn.

Many of the findings of the current study connect directly to existing motivational and student development literature and underscore the importance of considering motivational and developmental strategies in addition to instructional strategies when constructing a first-year seminar. In light of the current study's findings, I offer the following recommendations to administrators charged with overseeing first-year seminars and to first-year seminar instructors. First, be aware of the barriers that a one-credit, pass/fail class imposes on students' and instructors' motivation and assess whether the affordances offered by the existing structure outweigh the motivational limits imposed. The structure of a first-year seminar poses a motivational conundrum because the institution or department may be less likely to commit the time, effort, and money necessary to expand a first-year seminar into three credits, not to mention the additional instructor time and resources needed from the university to do so. In addition, students in the current study described low expectations prior to taking the seminar. Because the class was one-credit and pass/fail, they did not expect to work hard, nor did they expect to learn from their experience in the seminar. With first-year seminars being a primary intervention tool for students' retention to their second year, it is important to weigh the benefits of providing a more demanding seminar that may lead to greater motivational gains for students in the long run, with the drawbacks of depleted resources and potentially fewer students enrolled.

Second, administrators and instructors should consider the instructional, motivational, and developmental strategies necessary to foster motivation in first-year seminars and be sure that instructors either possess them or can learn them through training or an orientation. The findings of the current study point to the importance of having an instructor who can scaffold motivation into the classroom environment, especially when students begin the course with little to no motivation (Brophy, 2004). Using motivational tools including providing constructive feedback to challenge students and thereby deepen their motivation to learn (Brophy, 2004; Chickering \& Gamson, 1987, 1991; Svinicki, 2004), connecting academic content to students' personal lives (Baxter Magolda, 2004), and aiming to 
connect with students in their cognitive and motivational zones of proximal development (Brophy, 2004; Vygotsky, 1978) is the key to scaffolding motivation into the classroom with the hope that students will become more intrinsically motivated. It is likely that the instructor whom I observed had the skills to provide such interventions with students from the start because of her work with faculty development, but not all instructors have had similar training. It is important that administrators charged with recruiting faculty for first-year seminar courses provide sufficient support to them so that they receive the training they need to work with this unique population of students within the challenging structural context of a first-year seminar.

\section{Future Research}

The findings of the current study illustrate the importance of employing motivational strategies in firstyear seminar classrooms in order to ensure that students become engaged in the life of the mind. Additional research is needed to understand more about how students make meaning of their motivation to learn in varying types of first-year seminars, including those intended to be extended orientation sessions, those intended to build study skills, and those that are a requirement for all students. Furthermore, more longitudinal research is needed at the postsecondary level and with firstyear seminars in particular to understand how motivation evolves throughout students' time in college and what motivational strategies lay the most solid foundation from which to build upon as students develop.

\section{Conclusion}

The Boyer Commission (1998) saw the unique environment afforded by first-year seminars as an opportunity to assist students in building a foundation for success in college, hence their recommendation that these seminars be implemented on every campus. Their vision for the seminars was to provide space for a "professor to imbue new students with a sense of the excitement of discovery and the opportunities for intellectual growth inherent in the university experience" (p. 20). It is clear from the description that the Boyer Commission envisioned the first-year seminar as a catalyst for motivation, encouraging students to take advantage of everything a research university has to offer. As illustrated by the findings of the current study, students do not always enter a first-year seminar with an intrinsic desire to learn, and consequently that desire must be fostered and scaffolded by a patient, well-trained, and interested instructor. If first-year seminars are to reach the potential for which they were initially envisioned, university administrators and faculty must ensure that instructors have the curricular and motivational resources they need in order to be successful. This may mean that administrators take a hard look at the organizational structure of the seminars to determine whether they are truly setting students up to engage in the "wealth, diversity, scale, and scope of " everything that lies ahead for them at the university (Boyer Commission on Educating Undergraduates in the Research University, 1998, p. 19).

\section{References}

Barefoot, B. O. (1992). Helping first-year college students climb the academic ladder: Report of a national survey of freshman seminar programming in American higher education (Doctoral dissertation). College of William and Mary, Williamsburg 
Barefoot, B., Warnock, C., Dickinson, M., Richardson, S., \& Roberts, M. (1998). Exploring the evidence: Reporting outcomes of first-year seminars, vol. II (Monograph No. 11). Columbia: University of South Carolina, National Resource Center for the Freshman Year Experience and Students in Transition.

Barr, R. B., \& Tagg, J. (1995). From teaching to learning: A new paradigm for undergraduate education. Change, 27(6), 12.

Baxter Magolda, M. B. (2004). Learning partnerships model: A framework for promoting self-authorship. In M. B. Baxter Magolda \& P. M. King (Eds.), Learning partnerships: Theory and models of practice for self-authorship (pp. 37-62). Sterling, Va.: Stylus.

Boyer Commission on Educating Undergraduates in the Research University. (1998). Reinventing undergraduate education: A blueprint for America's research universities. Stony Brook: State University of New York at Stony Brook.

Brophy, J. (2004). Motivation to learn (2nd ed.). Mahwah, N.J.: Erlbaum

Chickering, A., \& Gamson, Z. (1987). Seven principles for good practice in undergraduate education. AAHE Bulletin, 39, 3-7.

Chickering, A., \& Gamson, Z. (1991). Applying the seven principles for good practice in undergraduate education. San Francisco: Jossey-Bass.

Creswell, J. W. (2007). Qualitative inquiry and research design: Choosing among five approaches (2nd ed.). Thousand Oaks: Sage.

Duderstadt, J. J. (2000). A university for the twenty-first century. Ann Arbor: University of Michigan Press.

Dweck, C. S., \& Leggett, E. L. (1988). A social/cognitive approach to motivation and personality. Psychological Review, 95, 256-73.

Fidler, P., \& Godwin, M. (1994). Retaining African-American students through the freshman seminar. Journal of Developmental Education, 17(3), 34-40.

Fidler, P., \& Hunter, M. (1989). How seminars enhance student success. In M. L. Upcraft \& J. N. Gardner (Eds.), The freshman year experience: Helping students survive and succeed in college (pp. 21637). San Francisco: Jossey-Bass.

Fidler, P., \& Moore, P. (1996). A comparison of effects of campus residence and freshman seminar attendance on freshman dropout rates. Journal of the Freshman Year Experience and Students in Transition, 8(2), 7-16.

Grant, H., \& Dweck, C. S. (2003). Clarifying achievement goals and their impact. Journal of Personality and Social Psychology, 85, 541-53.

Harackiewicz, J. M., Barron, K. E., Pintrich, P. R., Elliot, A., \& Thrash, T. (2002). Revision of achievement goal theory: Necessary and illuminating. Journal of Educational Psychology, 94, 638-45.

Keup, J. R., \& Barefoot, B. O. (2005). Learning how to be a successful student: Exploring the impact of first-year seminars on student outcomes. Journal of the First Year Experiences, 17(1), 11-47.

Koch, A. (2001). The first-year experience in American higher education: An annotated bibliography (Monograph No. 3; 3rd ed.). Columbia: University of South Carolina.

McGregor, H. A., \& Elliot, A. J. (2002). Achievement goals as predictors of achievementrelevant processes prior to task engagement. Journal of Educational Psychology, 94, 381-95.

Middleton, M. J., Kaplan, A., \& Midgley, C. (2004). The change in middle school students' achievement goals in mathematics over time. Social Psychology of Education, 7, 289-311. 
Patton, M. Q. (1990). Qualitative evaluation and research methods (2nd ed.). Newbury Park, Calif.: Sage Publications.

Sarafino, E. P., \& DiMattia, P. A. (1978). Does grading undermine intrinsic interest in a college course? Journal of Educational Psychology, 70(6), 916-21.

Simmons, G. (1995). The effects of a freshman seminar on at-risk, under-, over-, and low achievers. NACADA Journal, 15(1), 8-14.

Svinicki, M. D. (2004). Learning and motivation in the postsecondary classroom. Bolton, Mass.: Anker.

Vygotsky, L. S. (1978). Mind in society. Cambridge: Harvard University Press.

Wigfield, A., \& Eccles, J. (2000). Expectancy-value theory of achievement motivation. Contemporary Educational Psychology, 25, 68-81.

Yin, R. (1984). Case study research: Design and methods. Beverly Hills: Sage. 